\title{
MULTICURSO MATEMÁTICA: AVALIAÇÃO E APRIMORAMENTO'
}

ELIANE BIRMAN

ISA CRISTINA DA ROCHA LOPES

\section{RESUMO}

A investigação sobre aprendizagem tem incorporado medidas relacionadas com programas educacionais, gestão escolar e formação de professores, incluídas parcerias entre gestores públicos e instituições não governamentais, como é o caso do Programa Multicurso Matemática da Fundação Roberto Marinho. Para conhecer a contribuição do Programa, contou-se com avaliação externa que compreendeu: diagnóstico inicial, processo e resultados. Desenvolveu-se uma análise a partir de observações dos atores envolvidos, questionários contextuais e verificação da proficiência dos alunos em Matemática. A proficiência foi estimada utilizando-se a Teoria de Resposta ao Item Paramétrica, compatibilizando escalas com o Sistema de Avaliação da Educação Básica. Observou-se progresso nas médias de proficiência, mudanças nas perspectivas metodológicas dos professores, na dinâmica de planejamento e na reflexão sobre práticas escolares. 


\section{RESUMEN}

La investigación sobre el aprendizaje ha incorporado medidas relacionadas con programas educativos, gestión escolar y formación de profesores, que incluyen alianzas entre gestores públicos e instituciones no gubernamentales, como es el caso del Programa Multicurso Matemática de la Fundación Roberto Marinho. Para conocer la contribución del mismo, una empresa externa realizó una evaluación que constó de tres fases: diagnóstico inicial, proceso y resultados. Se desarrolló un análisis partiendo de la observación de las personas involucradas, de cuestionarios contextuales y de la verificación de la competencia de los alumnos de Matemática. El nivel de competencia fue estimado utilizando la Teoría de la Respuesta al Ítem Paramétrico, compatibilizando escalas con el Sistema de Evaluación de la Educación Básica. Se observó un progreso en los promedios de competencia, cambios en las perspectivas metodológicas de los profesores, en la dinámica de planificación y en la reflexión sobre prácticas escolares.

PALABRAS CLAVE FORMACIÓN DE PROFESORES •

EVALUACIÓN DEL APRENDIZAJE • EDUCACIÓN CONTINUA• EVALUACIÓN DEL PROGRAMA.

\section{ABSTRACT}

Studies involving learning have incorporated some measures related to educational programs, school management and teacher training. The establishment of partnerships between public administrators and non-governmental institutions has been fruitful, giving rise to programs like the Multicurso Matemática of the Roberto Marinho Foundation. To assess the programs' contribution, an external company was appointed to evaluate the results. The assessment had three stages: initial diagnosis, process and outcome. The analysis was based on observations of the agents involved, as well as contextual questionnaires, assessing student proficiency in mathematics. The level of proficiency was estimated using the Parametric Item Response Theory, harmonizing scales with the Basic Education Assessment System. Results showed an improvement in the proficiency averages, changes in teachers' methodological perspectives and planning dynamics and reflections on teaching practices. 


\section{INTRODUÇÃO}

Este artigo aborda as contribuições do Programa Multicurso Matemática da Fundação Roberto Marinho (FRM) para a melhoria da qualidade dos processos educacionais a partir da avaliação de seus resultados, realizada pela Innova Pesquisa e Assessoria, no decorrer dos anos de 2008, 2009 e 2010.

O Programa Multicurso Matemática é uma proposta formativa semipresencial destinada a professores, coordenadores pedagógicos e diretores de escolas das redes públicas de ensino médio, para promover o aprimoramento do ensino-aprendizagem da Matemática. Assim, em 2008, a Secretaria de Estado da Educação do Espírito Santo (Sedu-ES) firmou parceria com a FRM, para desenvolver um programa de formação continuada em Matemática, com os educadores que atuam no ensino médio (EM) em toda a rede estadual.

Fundamentalmente, a avaliação desenvolvida pela Innova identificou se o Programa Multicurso Matemática 2008 atingiu os objetivos previstos. Para tanto, investigou os resultados do Programa no período compreendido entre 2008 a 2010. 
A pesquisa de avaliação contempla os seguintes momentos articulados: diagnóstico inicial (2008) e avaliação em processo (2008/2009); análise do resultado da Fase I (2009) e análise do resultado da Fase II (2010). Seu desenho incorpora, portanto, tanto um amplo diagnóstico inicial - linha de base - como o acompanhamento de pontos-chave do processo e a análise dos resultados produzidos pelo programa (Fases I e II).

Em relação ao aluno de Matemática do ensino médio capixaba, a avaliação observou não apenas o desempenho, mas também a aprendizagem em Matemática, por meio de um estudo longitudinal no qual a mesma amostra de escolas e de estudantes foi observada em três momentos - T1, T2 e T3, conforme ilustração abaixo.

FIGURA 1 - Esquema da avaliação

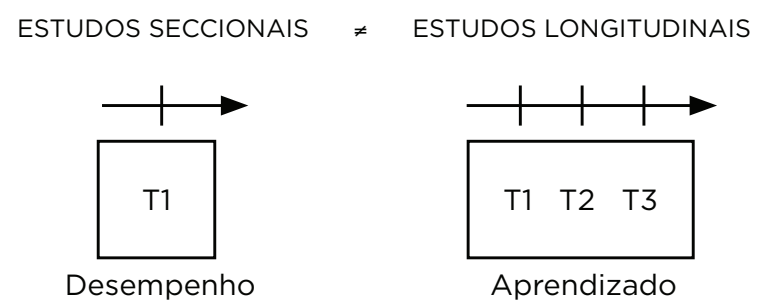

Fonte: Elaboração das autoras.

Em T1 medimos o panorama da situação do ensino-aprendizagem em Matemática, no momento de implantação do Multicurso Matemática. No T2 o momento final do primeiro ciclo de avaliação, e no T3 o final do segundo ciclo de avaliação, no qual foi possível perceber avanços, estabilização ou retrocessos no aprendizado e nas práticas pedagógicas realizadas pelos atores envolvidos no Programa.

No Brasil, os projetos de avaliação educacional em larga escala já consolidados são, majoritariamente, surveys seccionais que mensuram o desempenho dos alunos em um dado momento, relacionando-o com o levantamento de informações contextuais sobre os estudantes e suas escolas. Nesse caso, tem-se a medida de um conjunto de habilidades que os alunos possuem, mesmo que uma parcela dessas habilidades não tenha sido construída no contexto escolar no qual ocorreu a avaliação. 
Diferentemente dessa tendência, a avaliação proposta nesta pesquisa apresenta um desenho longitudinal, dessa forma contribuindo para o aprimoramento das avaliações educacionais brasileiras. Entende-se que para estabelecer uma medida de aprendizagem é necessário que o mesmo aluno seja avaliado mais de uma vez, verificando-se o conteúdo que ele aprendeu durante um determinado período. Assim, a diferença desta forma de medição resulta da influência do contexto, já que focaliza a contribuição da escola e também a do Multicurso Matemática.

A avaliação da aprendizagem foi, portanto, efetuada mantendo a mesma amostra de alunos, de forma a estabelecer as bases para o monitoramento dos participantes do programa Multicurso Matemática nos anos subsequentes, pois o impacto do programa pode ocorrer não apenas no curto, mas no médio prazo.

Por se tratar de um processo cognitivo, envolvendo o desenvolvimento gradual da aquisição de conhecimentos e de apropriação de um novo paradigma de ensino, os resultados não são imediatos. Como referência temporal para a medição desses impactos, cita-se o Índice de Desenvolvimento da Educação Básica (Ideb), que estabeleceu prazo longo para a elevação de resultados referentes ao processo educativo.

A consolidação ora apresentada contém a análise dos resultados relativos aos indicadores sobre a aprendizagem em Matemática dos alunos do ensino médio da rede estadual do Espírito Santo e respectivos perfis sociodemográficos, nos períodos citados. Além do perfil, foram considerados dados contextuais e percepções dos professores de Matemática participantes da Fase III do programa Multicurso Matemática.

A avaliação foi norteada pelo Quadro Lógico do programa, que contém a descrição de vários indicadores de resultados, dentre os quais foram considerados: diferença positiva obtida pelos alunos ( $3^{\circ}$ ano) do EM da rede estadual no Sistema de Avaliação da Educação Básica (Saeb)/Prova Brasil anterior e posterior ao Multicurso; diferença positiva do desempenho dos alunos da amostra ( $3^{\circ}$ ano) do EM nos testes de aprendizado do Multicurso; percepção mais positiva (gosto e facilidade) dos alunos em relação aos conteúdos de Matemática; e percepções dos professores em relação aos alunos e ao ensino de Matemática, a indicadores contextuais, motivação e adoção de novas práticas pedagógicas, e às contribuições do Multicurso. 
O artigo está estruturado em três partes: na primeira parte apresenta-se a perspectiva metodológica da pesquisa de avaliação; na segunda parte descrevem-se os principais resultados da pesquisa, no tocante à proficiência dos alunos e à percepção dos professores sobre a dinâmica de planejamento, didática das aulas e novas estratégias de ensino; e na terceira e última parte, tecem-se as considerações finais sobre as contribuições do projeto Multicurso Matemática e de seu processo de avaliação para a melhoria da qualidade da educação brasileira.

\section{PERSPECTIVA METODOLÓGICA DA PESQUISA DE AVALIAÇÃO}

A experiência de avaliação nas áreas sociais (BOAVENTURA, 2009; GIL, 1999; MINAYO, 2003), nas quais a educação está inserida, aponta para a impossibilidade de se estabelecer um único método. É necessário construir referenciais que possam dar conta da riqueza das ações que acontecem nos programas educacionais e que, muitas vezes, não é considerada devido a visões redutoras da realidade.

Na perspectiva de superar o reducionismo, o desenho metodológico da avaliação apresentada neste artigo procurou integrar abordagens de caráter qualitativo com as de características quantitativas, a fim de construir interpretações mais abrangentes e complexas para os múltiplos fenômenos da realidade analisada, constituída por dimensões históricas, políticas, econômicas e culturais. Todavia, na Avaliação da Fase III do programa adotou-se apenas a abordagem quantitativa, em virtude de restrições orçamentárias.

A avaliação da Fase I contou com a participação de um amplo conjunto de sujeitos. Além de alunos e professores, foram envolvidos: equipes técnicas da Sedu-ES, superintendentes regionais, técnicos das Subsecretarias Regionais de Educação (SRE), coordenadores de grupos de estudo, diretores escolares e coordenadores pedagógicos. Na Fase II, entretanto, participaram como sujeitos apenas alunos e professores do ensino médio, e foram avaliados por meio dos procedimentos descritos a seguir. 


\subsection{VERIFICAÇÃO DA PROFICIÊNCIA}

\section{DOS ALUNOS EM MATEMÁTICA}

Realizada a partir da aplicação de teste de Matemática e questionário sociodemográfico, desenvolvido especificamente para alunos do $3^{\circ}$ ano do ensino médio nas 78 escolas selecionadas para a amostra da avaliação do Multicurso, contemplando, aproximadamente, 10.440 alunos.

Para captar a aprendizagem em Matemática foi realizado um estudo longitudinal. Em 2008, os alunos que estavam cursando o $1^{\circ}$ ano do ensino médio responderam aos testes de proficiência e aos questionários contextuais, cujos resultados configuram o perfil de entrada na rede de ensino estadual. Em 2009, estes mesmos alunos participaram de uma segunda avaliação, mas, além deles, foram incorporados os novos alunos que ingressaram no $2^{\circ}$ ano nas escolas sorteadas. Em 2010, participaram da terceira avaliação os alunos do $3^{\circ}$ ano que cursaram o $2^{\circ}$ ano em 2009, e nela foram incluídos também os alunos transferidos de outras unidades escolares, os alunos que ficaram retidos ou repetiram o $2^{\circ}$ ano do ensino médio e que permaneceram na escola, e os alunos que, em 2008, estavam no $1^{\circ}$ ano do ensino médio e ficaram defasados em relação à série. A proficiência foi estimada utilizando-se a Teoria de Resposta ao Item Paramétrica, com o propósito de equalizar as escalas para os diferentes anos e também com a escala do Saeb.

\subsection{SURVEY JUNTO AO UNIVERSO DE}

PROFESSORES ENVOLVIDOS NO PROGRAMA

Durante o mês de outubro de 2008 foram distribuídos questionários sociodemográficos contextuais a todos os docentes participantes do programa Multicurso Matemática. Procurou-se, assim, traçar na Fase I (2008) da avaliação, mediante questionários autoaplicáveis, o perfil de entrada no programa (Marco Zero), incluindo expectativas em relação ao Multicurso Matemática e às práticas pedagógicas de ensino em Matemática. No caso dos professores, não foi estabelecida uma amostra, buscando-se alcançar todos os docentes participantes.

Em 2009, uma segunda avaliação foi promovida, com características e abrangências semelhantes à Fase I, excetuando as entrevistas com equipe da Secretaria de Educação, para que fosse possível traçar a evolução desse instrumental no período. Tal como em 2008, foram enviados questionários a todos os 
professores envolvidos, incluindo-se os que ingressaram no programa apenas em 2009. Finalmente, em 2010 foi realizada a Fase III da avaliação, igualmente destinada a todos os professores envolvidos no Multicurso Matemática, incluindo-se aqueles que não participaram das etapas anteriores de avaliação.

\section{PRINCIPAIS RESULTADOS DA AVALIAÇÃO}

\subsection{SOBRE OS ALUNOS}

Nesta seção, o enfoque de análise é o aprendizado dos alunos em Matemática. Para procedê-la, faz-se necessário destacar os indicadores de resultados pretendidos pelo Multicurso Matemática em relação a:

- Evolução do perfil sociodemográfico;

- Diferença positiva do desempenho, tanto nos testes de Proficiência da Avaliação do Multicurso $\left(1^{\circ}, 2^{\circ}\right.$ e $3^{\circ}$ ano) como no Saeb $\left(3^{\circ} \mathrm{ano}\right)$ do ensino médio da rede estadual (2009/2007);

- Percepção positiva da importância da Matemática na vida e na relação dos alunos com os conteúdos de Matemática.

No instrumento da avaliação de 2010 foram mantidas as variáveis selecionadas para as avaliações anteriores, associadas a construtos definidos a partir de teorias e resultados de pesquisas educacionais nacionais e internacionais. Nessa perspectiva, a literatura vem enfatizando, de forma recorrente, que aspectos socioeconômicos e demográficos têm grande influência nos resultados educacionais (COLEMAN et al., 1966; CUNHA, 1975).

Além desses aspectos, é relevante a mensuração de outras características dos alunos e de suas famílias, que guardam relação com o desempenho educacional. Assim, no questionário do aluno foi privilegiada, além da caracterização sociodemográfica, o capital cultural, o capital social, as práticas de estudo e a percepção dos alunos sobre a escola e sobre as práticas pedagógicas dos seus professores de Matemática. Essa caracterização foi feita a partir de discriminantes individuais como idade, gênero, cor e outros aspectos apontados como importantes pela literatura e pelo contexto específico do estudo em pauta, que permitem a divisão dos estudantes em subgrupos. 
O capital cultural é um conceito incorporado aos estudos educacionais a partir dos escritos de Pierre Bourdieu sobre reprodução social. Lareau (1987) define capital cultural como o conjunto dos bens culturais transmitidos pelas diferentes ações pedagógicas familiares. Na análise desenvolvida, a caracterização do capital cultural do aluno leva em conta seus hábitos de leitura, a assiduidade em frente à televisão, a frequência com que ele navega na internet, as conversas com amigos, a prática de esportes, entre outros, que definem um ambiente mais ou menos favorável às realizações educativas.

No que se refere ao capital social, os preceitos são encontrados em Coleman et al. (1966), além dos trabalhos de Willms (1998) e de Silva e Hasenbalg (2000), entre outros. O capital social é definido pela quantidade de vínculos sociais com que o indivíduo pode contar no lugar em que vive para facilitar a sua ação dentro da estrutura social. Na família, este conceito é traduzido nas relações entre pais e filhos, sendo que o questionário do aluno inclui questões sobre a estrutura familiar (com quem mora, por exemplo).

\subsubsection{EVOLUÇÃO DO PERFIL SOCIODEMOGRÁFICO}

Em 2010, continuou sendo do sexo feminino a maioria dos estudantes participantes da pesquisa. Além disso, a maior parte dos pesquisados se autodeclarou de cor parda, afirmou ter religião - principalmente cristã -, e mais de $80 \%$ possuíam renda familiar de até quatro salários-mínimos. Todavia, a comparação dos dados de 2010 com as avaliações anteriores mostrou que houve aumento na proporção de estudantes do sexo feminino e na proporção de estudantes de cor branca, sendo que a renda dos alunos era mais baixa, proporcionalmente.

Quanto à escolaridade dos pais, considerada baixa nos três anos da investigação, verificou-se que cerca de um terço deles tinha até a $4^{\mathrm{a}}$ série do ensino fundamental, confirmando o fenômeno do aumento de escolaridade intergeracional no país.

Os resultados de avaliações nacionais no Brasil, como os do Saeb, indicam que o fator hábito de leitura está associado a um melhor desempenho dos alunos em todas as séries avaliadas, por isso, o questionário socioeconômico averiguou esses hábitos. As respostas em 2008, 2009 e 2010 indicaram que o 
tipo de leitura preferida é o jornal: em 2008/2009, aproximadamente $40 \%$ dos alunos liam jornais com assiduidade, índice que subiu para $42 \%$ em 2010 . Com relação à leitura de livros de literatura, nas três avaliações os extremos praticamente se equipararam: cerca de um quarto dos alunos lia livros de literatura com bastante assiduidade e outro quarto deles nunca ou quase nunca fazia este tipo de leitura.

A leitura de revistas de informação geral também estava incluída nas atividades da maioria dos alunos, sendo observada nas três avaliações. Embora poucos tivessem o hábito de ler com assiduidade este tipo de revista, observou-se crescente o percentual daqueles que o faziam sazonalmente. Merece destaque, embora apresente percentual decrescente, a quantidade de alunos que nunca ou quase nunca realizava estas leituras: 30\%, em 2010.

Os questionários respondidos pelos alunos também investigaram o uso cotidiano do tempo fora da escola. Para a maioria, o tempo alocado nos trabalhos domésticos continuou variando entre uma e quatro horas de atividades por dia. Apenas 19\% indicaram não realizar estas atividades. Em relação ao estudo e ao dever de casa, verificou-se que houve um pequeno aumento no percentual dos estudantes que dedicavam até duas horas diárias ao estudo fora da escola: de $26 \%$ em 2009 para $28 \%$ em 2010. Chama a atenção o fato de um décimo dos alunos, nas três avaliações, não realizarem atividades extraescolares.

Conforme observado nos relatórios de avaliação de 2008 e 2009, este é um resultado importante, porque o dever de casa pode ser considerado um fator de impacto no rendimento escolar. Dados do Saeb demonstraram que os alunos que fazem dever de casa têm um desempenho escolar bastante superior ao daqueles que não o fazem.

Outro aspecto investigado que também contribui para explicar a baixa carga horária de estudos em casa foi a condição de trabalho dos alunos. No período analisado, o percentual de alunos que trabalhavam aumentou de $38 \%$, em 2008 , para $44 \%$, em 2009, e para 46,3\% em 2010, e os motivos para inserção no mercado de trabalho estavam, em sua maioria, relacionados às condições econômicas de suas famílias. 
De um modo geral, a partir dos resultados alcançados pelos estudantes no teste cognitivo Multicurso Matemática 2010, pode-se aferir que a maioria dos alunos teve índice de acerto superior ao verificado em 2009. Estimou-se a proficiência a partir da Teoria de Resposta ao Item Paramétrica, com o propósito de harmonizar as escalas para os diferentes anos e também com a escala do Saeb. A melhora expressiva foi observada em Números e no Tratamento da informação.

Como o teste de Matemática aplicado no Multicurso apresentava itens comuns ao Saeb, foi possível construir uma medida de desempenho da avaliação do Multicurso 2008, 2009 e 2010, na mesma escala de proficiência do Saeb e, também, da Prova Brasil (Tabela 1). Dessa forma, o desempenho na avaliação do Multicurso Espírito Santo - ES 2008, 2009 e 2010 pode ser comparado ao da Prova Brasil da $8^{\text {a }}$ Série do ensino fundamental nos anos de 2005 e 2007, bem como ao desempenho do Saeb para o $3^{\circ}$ ano do ensino médio em 2009 (Gráfico 1).

TABELA 1 - Escala de proficiência do Saeb, Prova Brasil e Multicurso Matemática

\begin{tabular}{c|c}
\hline \multicolumn{2}{c}{ ESCALA DE PROFICIÊNCIA - MATEMÁTICA } \\
\hline Nível & Faixa \\
\hline 0 & Abaixo de 125 \\
1 & $125-150$ \\
2 & $150-175$ \\
3 & $175-200$ \\
4 & $200-225$ \\
5 & $225-250$ \\
6 & $250-275$ \\
7 & $275-300$ \\
8 & $300-325$ \\
9 & $325-350$ \\
10 & Acima de 350 \\
\hline
\end{tabular}

Fonte: MEC, Prova Brasil/Saeb (2009). 
GRÁFICO 1 - Proficiência média em Matemática, por avaliação Rede estadual do Espírito Santo
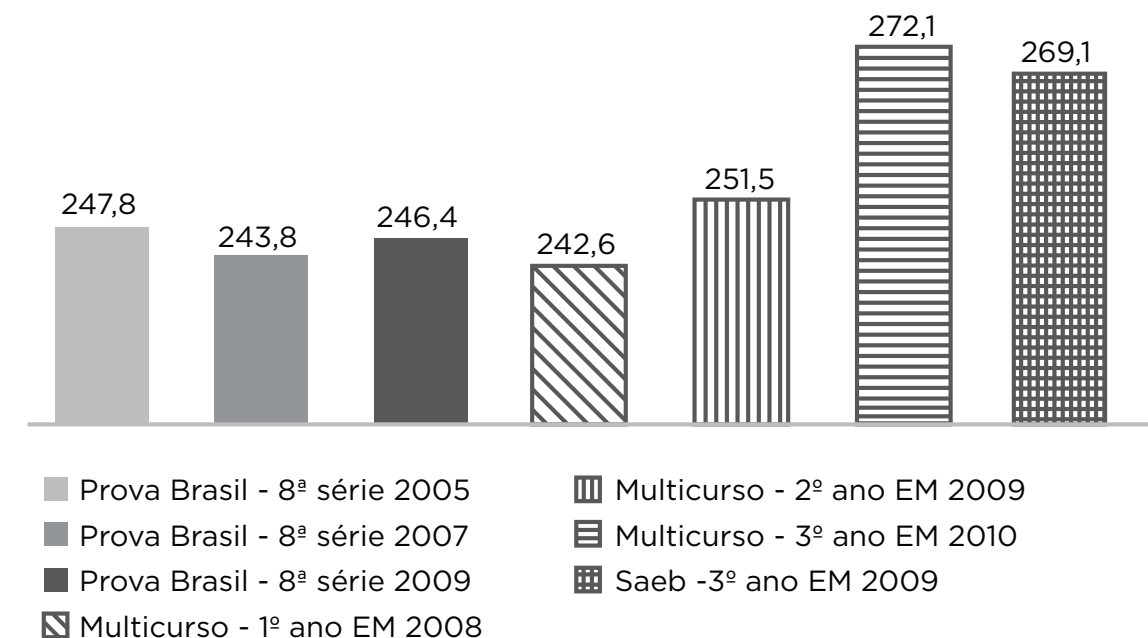

Fonte: Avaliação externa do Multicurso Matemática ensino médio ES 2008, 2009, 2010, Saeb 2009, Prova Brasil 2005, 2007, 2009.

Os resultados apontados no Gráfico 1 indicam que na Prova Brasil houve um recuo na proficiência dos alunos de $8^{\mathrm{a}}$ série no ES, entre 2005 e 2007, o que foi observado também em outros estados brasileiros. O resultado do primeiro teste do Multicurso, em 2008, foi praticamente igual à média da rede estadual do ES na Prova Brasil na $8^{\mathrm{a}}$ série do ensino fundamental no ano de 2007. A proximidade cronológica entre a Prova Brasil, ocorrida em novembro de 2007, e a avaliação do Multicurso Matemática, em agosto de 2008, pode explicar o resultado, pois, tradicionalmente, grande parte do primeiro semestre do $1^{\circ}$ ano do ensino médio é dedicada à revisão e à consolidação de habilidades aprendidas ao longo do ensino fundamental.

Comparando as médias de proficiência captadas exclusivamente pelos testes do Multicurso Matemática, observou-se uma melhora nas duas primeiras avaliações: a média geral saiu de 242,6 para 251,5 pontos em 2009, passando do nível 5 para o nível 6 e superando todos os resultados das avaliações anteriores. Os resultados do teste de 2010, quando comparados aos de 2009, apresentaram um aumento ainda maior na proficiência dos alunos, saltando a média de 251,5 para 272,1. Esse crescimento significativo de 20 pontos na escala não resultou em mudança de nível, embora a média estivesse muito próxima do limite inferior do nível 7 (Tabela 1). O desempenho avaliado no Multicurso Matemática em 2010 permaneceu muito 
próximo ao desempenho da rede estadual do ES avaliado pelo Saeb em 2009.

Os resultados do desempenho médio em cada um dos estratos evidenciaram variações importantes dentro da rede estadual, quando são comparados os resultados de 2008 e 2009 com os de 2010. A média geral da rede estadual foi de 272,1 pontos em 2010, sendo os grupos com desempenho abaixo desse valor pertencentes às SRE de: Linhares, Carapina, Cariacica, Vila Velha e, ainda, das Escolas Técnicas. No grupo dos que apresentaram melhor desempenho se destaca a SRE de Afonso Cláudio, com 29 pontos acima da média geral. Em contrapartida, a SRE de Cariacica continuou sendo a regional com o desempenho mais baixo, com 17 pontos abaixo da média geral.

Em relação à média de desempenho em Matemática, por turno de ensino, em 2008, 2009 e 2010, foram verificadas pequenas diferenças entre os alunos do turno da manhã e da tarde, nas três etapas da avaliação. Entre 2008 e 2009, o maior crescimento no desempenho ocorreu entre os alunos do período noturno. Já em 2010, significativos avanços ocorreram nos turnos da manhã, que apresentou uma diferença de 25 pontos, e da tarde, com a disparidade de 22 pontos, enquanto no noturno o aumento foi de 15 pontos na escala do desempenho.

Com relação à distribuição dos alunos pelos níveis de proficiência (Gráfico 2), verifica-se um progresso significativo em relação aos resultados de 2009, pois houve redução nos percentuais referentes às faixas de baixa proficiência e aumento nas faixas mais altas. No entanto, observa-se que, em 2010, $53 \%$ dos alunos estavam nos níveis 5, 6 e 7, e 13\% estavam no nível 8, considerado como satisfatório para o final do ensino fundamental e médio. Cabe enfatizar que $17 \%$ dos alunos ainda estavam nos níveis correspondentes às habilidades muito básicas - abaixo do nível 5.

Na comparação dos resultados da proficiência, considerando o perfil dos alunos, é possível afirmar que nas três etapas da pesquisa a média de proficiência apresentou-se maior entre os alunos brancos e os do sexo masculino. Em relação à idade, nas duas primeiras avaliações os mais jovens alcançaram melhores desempenhos, o que não ocorreu em 2010. Além desses grupos de alunos, em 2009 e em 2010 a proficiência também foi maior entre os religiosos. 
GRÁFICO 2 - Distribuição (\%) dos alunos da Rede Estadual do Espírito Santo, segundo o nível de proficiência em Matemática

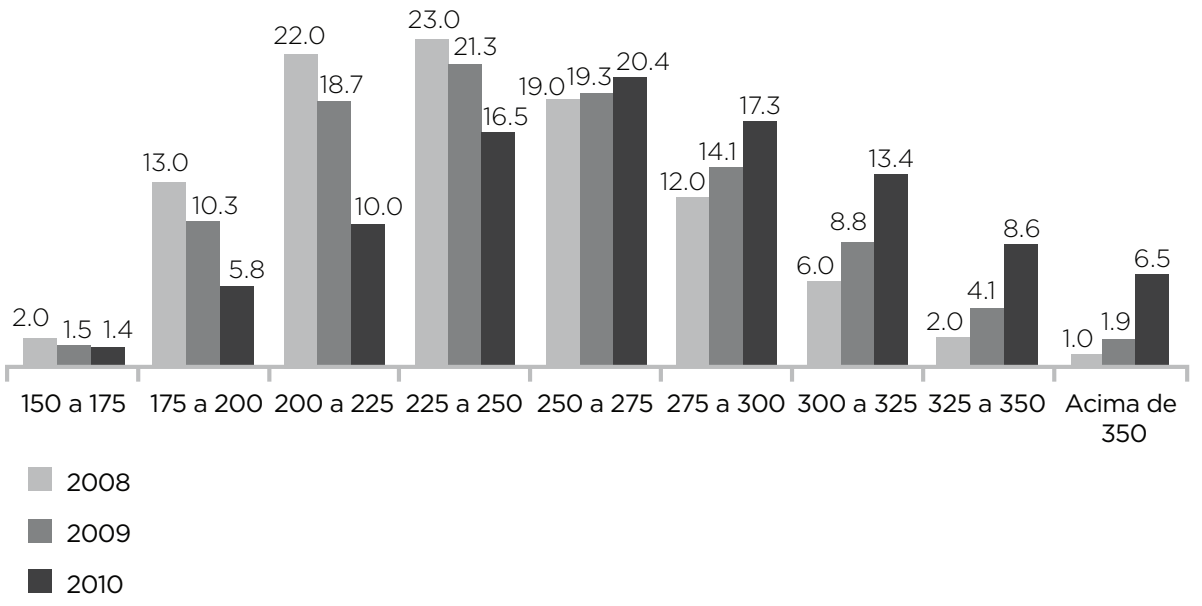

Fonte: Avaliação externa do Multicurso Matemática ensino médio ES 2008, 2009, 2010.

TABELA 2 - Proficiência média, em Matemática, dos alunos da Rede Estadual do Espírito Santo, segundo variáveis de perfil

\begin{tabular}{|c|c|c|c|}
\hline \multirow{2}{*}{ VARIÁVEIS } & \multicolumn{3}{|c|}{ PROFICIÊNCIA } \\
\hline & 2008 & 2009 & 2010 \\
\hline Total & 242,6 & 251,5 & 272,1 \\
\hline \multicolumn{4}{|l|}{ Sexo } \\
\hline Masculino & 245,2 & 252,6 & 276,6 \\
\hline Feminino & 243,7 & 251,1 & 269,6 \\
\hline \multicolumn{4}{|l|}{ Cor } \\
\hline Branco & 251,6 & 261,0 & 283,3 \\
\hline Pardo & 242,8 & 249,8 & 268,6 \\
\hline Preto & 237,8 & 243,4 & 266,2 \\
\hline Amarelo & 240,9 & 247,4 & 262,1 \\
\hline Indígena & 239,2 & 242,5 & 264,2 \\
\hline Total & 244,4 & 251,8 & 272,1 \\
\hline \multicolumn{4}{|l|}{ Religião } \\
\hline Sem religião & & 243,0 & 262,1 \\
\hline Católica & & 255,2 & 275,3 \\
\hline Evangélica & & 251,9 & 272,2 \\
\hline Outras religiões & & 243,7 & 282,2 \\
\hline
\end{tabular}

Fonte: Avaliação externa do Multicurso Matemática ensino médio ES 2008, 2009, 2010.

Uma das evidências estabelecidas de forma mais estável no campo da sociologia da educação diz respeito às relações existentes entre desigualdades sociais e condições de oferta educacional. Inúmeras pesquisas atestam que o contexto geográfico onde 
a escola se insere desempenha papel relevante na distribuição social da educação (ALBERNAZ; FERREIRA; FRANCO, 2002; FRANCO; MANDARINO; ORTIGÃO, 2001).

Em termos sociais e econômicos, as populações dos municípios capixabas são bem diferentes entre si. Com a finalidade de realizar uma análise capaz de captar esta heterogeneidade, foi criada uma medida de nível socioeconômico (NSE), estimada para o conjunto de alunos avaliados e a escala foi construída a partir da utilização de análise de componentes principais, considerando indicadores de posse de bens econômicos (bens duráveis), nível de escolaridade dos pais e renda familiar.

Os alunos das SRE de Carapina, Vila Velha e os das escolas que ofereciam cursos profissionalizantes continuaram sendo os que possuíam melhores condições socioeconômicas e, em 2010, a SRE de Cariacica passou a integrar esse grupo. Estas escolas reúnem, majoritariamente, os alunos da região de Grande Vitória e dos municípios arredores. As escolas localizadas na zona rural e nas Superintendências de Colatina e Guaçuí são compostas por estudantes cujas condições socioeconômicas são menos favorecidas.

Uma análise exploratória descritiva permitiu associar o desempenho em Matemática com as características sociais e econômicas dos alunos, tanto para a rede estadual em geral, quanto para cada um dos estratos investigados. De modo geral, aqueles com NSE baixo ficaram, aproximadamente, três pontos abaixo da média geral de proficiência da rede, nas três avaliações.

GRÁFICO 3 - Desempenho médio, em Matemática, dos alunos da Rede Estadual do Espírito Santo, segundo o NSE

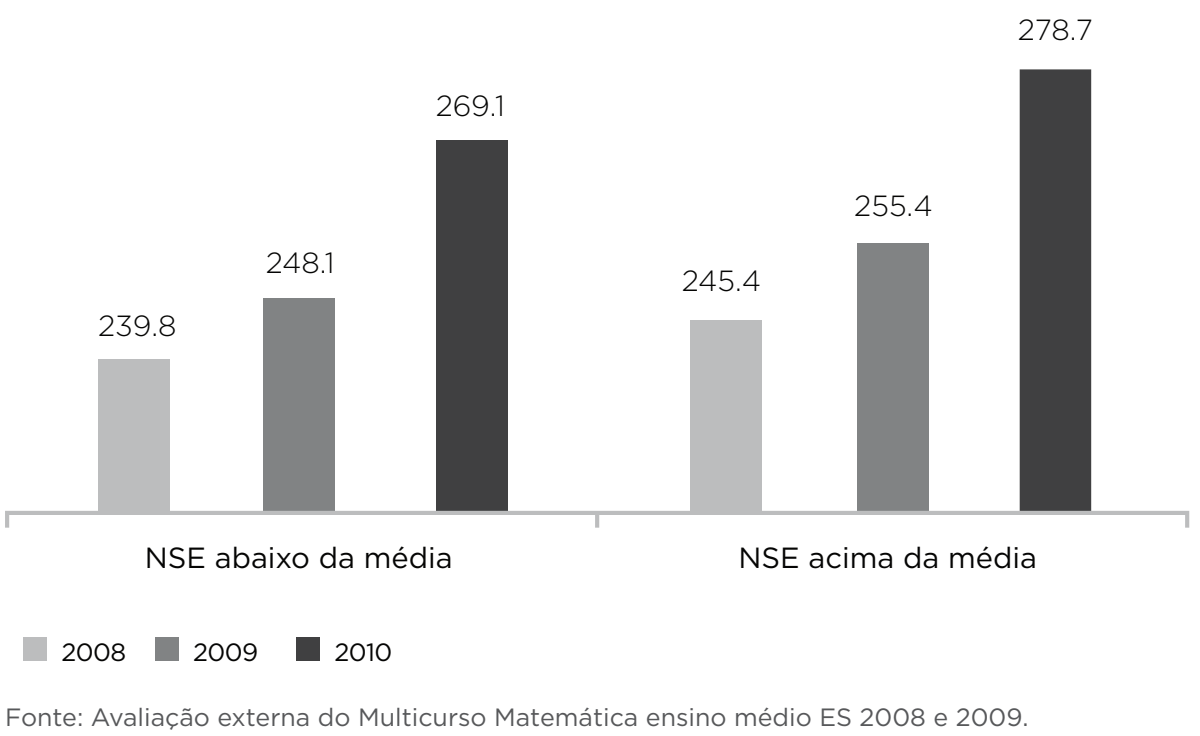


Pode-se observar, entretanto, que a SRE de Afonso Cláudio atendia a alunos com NSE abaixo da média e possuía o desempenho mais elevado (Gráfico 4). Já nas Superintendências de Carapina e Vila Velha, o desempenho situava-se abaixo da média da rede estadual, apesar de elas atenderem os alunos com as melhores condições socioeconômicas.

GRÁFICO 4 - Dispersão entre o desempenho médio dos alunos da Rede Estadual do Espírito Santo em 2010 e o NSE médio por SRE

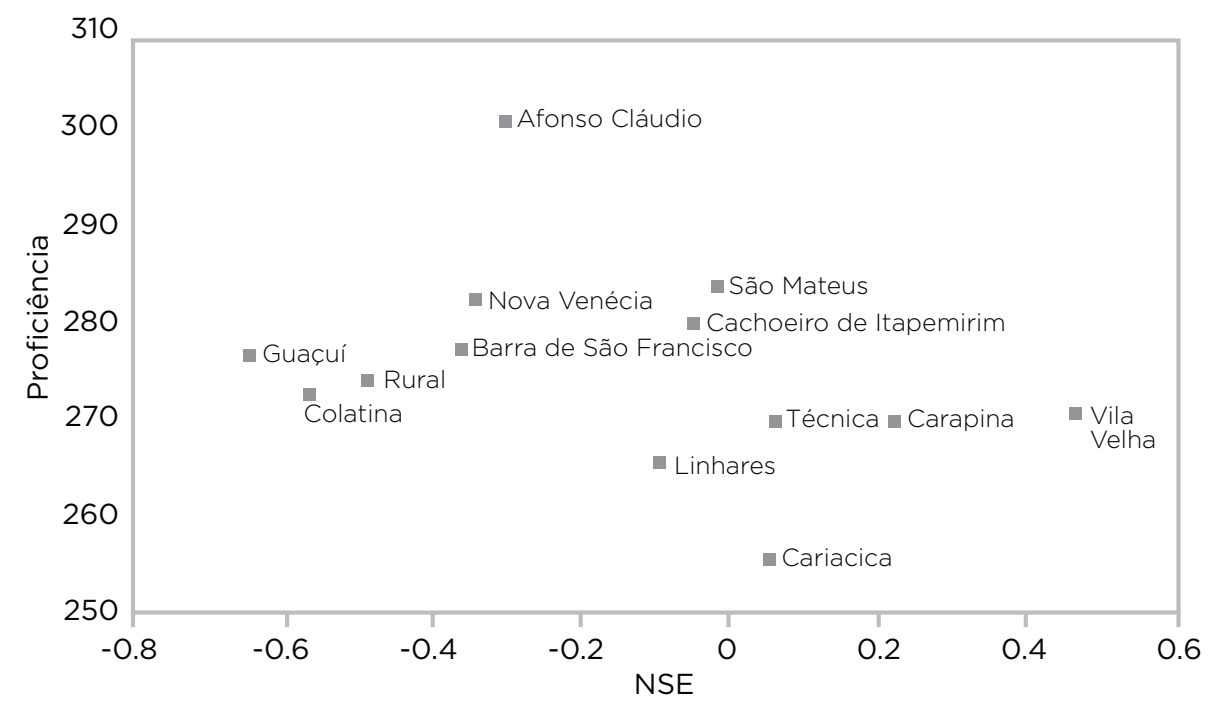

Fonte: Avaliação externa do Multicurso Matemática ensino médio ES 2010.

\subsubsection{PERCEPÇÃO DA IMPORTÂNCIA DA MATEMÁTICA}

\section{NA VIDA DOS ALUNOS}

No período analisado, verificou-se ligeiro declínio no percentual de valorização da instituição escolar por parte dos alunos, uma vez que, em 2008 , 64\% deles atribuiriam nota 10 para a importância da escola em suas vidas, índice que chegou a $60 \%$ em 2009, e 61\% em 2010. Já no que concerne à Matemática, a percepção mostrou-se menos expressiva, pois, em 2008, 44\% dos estudantes atribuíram nota 10 para a importância dessa disciplina em suas vidas, percentual que caiu para $43 \%$ em 2009 e chegou a $40 \%$ em 2010.

A esse respeito, em que pese a conhecida impressão de que a Matemática é um "bicho papão", os alunos participantes dos grupos focais, nas avaliações de 2008 e 2009, não a confirmaram nem indicaram gostar menos da Matemática em virtude de suas eventuais dificuldades. O que destacaram, nos 
dois momentos, foi a relação entre gostar de qualquer matéria e da forma de ensinar do professor.

\subsection{SOBRE OS PROFESSORES}

Nesta seção, a análise apresentada focaliza a percepção dos professores de Matemática sobre o projeto Multicurso. Para tanto, faz-se necessário recuperar os indicadores de resultados pretendidos pelo Multicurso Matemática em relação a:

- Evolução do perfil sociodemográfico;

- Percepções dos professores em relação: aos alunos e ao ensino de Matemática; aos indicadores contextuais, motivação e adoção de novas práticas pedagógicas; às contribuições do Multicurso Matemática.

\subsubsection{EVOLUÇÃO DO PERFIL SOCIODEMOGRÁFICO}

Como ocorreu em 2008 e em 2009 (56\% e 50,4\%, respectivamente), em 2010 a maior parte dos professores respondentes continuava sendo do sexo feminino (58\%), com idade igual ou superior a 30 anos (73\%), formação superior em Matemática $(71,1 \%)$ e sem outra atividade profisional além da docência $(77,1 \%)$.

De forma geral, houve poucas alterações no período compreendido entre 2008 e 2010. Em relação à renda familiar da maioria dos professores, igual ou superior a quatro salários mínimos, o percentual obtido em 2010 (72,7\%) foi bastante aproximado do verificado em 2008 (72,3\%). Quanto à experiência profissional, o percentual de professores com mais de dez anos de magistério aproximava-se de 50\%, com pequena variação nas três fases da pesquisa.

Verificou-se também o aumento de docentes com vínculo efetivo a partir de 2009 (36\%), tendência mantida em 2010 (37,7\%). Ressalta-se que, apesar da redução dos percentuais de professores com vínculo temporário, quando se procedeu à comparação entre os anos de 2008 e de 2010 os índices permaneceram elevados $(59,1 \%)$.

Do ponto de vista da escolaridade, o conjunto investigado de professores, em 2010, apresentou quantidade superior de docentes com pós-graduação lato sensu. Houve um aumento de 25,7\% em relação à situação de 2008, compatível com o alto índice de professores matriculados em cursos de especialização. 


\subsubsection{PERCEPÇÕES DOS PROFESSORES:}

OS ALUNOS E O ENSINO DA MATEMÁTICA, EXPECTATIVAS

\section{DOS PROFESSORES EM RELAÇÃO AOS ALUNOS}

As pesquisas em sociologia da educação têm reiteradamente identificado a relevância das expectativas dos professores sobre os alunos em termos de suas perspectivas ou chances de sucesso escolar e eventual mobilidade social (SAMMONS et al., 1995) e seu potencial de impacto no desempenho escolar.

Em 2010, a maioria dos professores indicou que conhecia os resultados do Saeb, das Provas de Aferição do Ensino Básico (Paeb) e do Ideb. Portanto, suas expectativas em relação aos alunos estavam pautadas nos resultados oficiais de avaliação da aprendizagem no Espírito Santo. Em termos gerais, houve uma tendência de ampliação das expectativas desses professores em relação ao futuro dos alunos.

É preciso considerar que tais expectativas foram desenvolvidas a partir de um conjunto muito extenso de fatores, marcados também pela conjuntura socioeconômica e política local e nacional. Por outro lado, o fato de os professores já terem diante de si alunos num estágio mais avançado de escolarização, pode ter influenciado suas expectativas em relação ao grupo.

\subsubsection{OS PROFESSORES E O ENSINO}

\section{DE CONTEÚDOS DA MATEMÁTICA}

De maneira geral, percebeu-se que, em relação a todos os conteúdos de todas as séries, expressiva parcela dos professores consultados em 2008, 2009 e 2010 sentia algum tipo de desconforto para ensinar um ou mais conteúdos da Matemática, sendo Equação de Segundo Grau o tema que promoveu maior conforto aos professores. Chama a atenção os baixos índices encontrados em relação a um maior conforto para ensinar, por exemplo, Progressão Geométrica/Quadrática, Trigonometria e Função Afim em 2008 (10,6\%, 16,5\% e 19,8\%, respectivamente), Progressão Geométrica/Quadrática e Trigonometria (19,2\% e 26\%, respectivamente) em 2009, e Função Exponencial, Trigonometria e Matrizes, e Sistemas de Equações (1\%, 3,1\% e 3,2\% respectivamente) em 2010. 
TABELA 3 - Opinião dos professores sobre a dificuldade para ensinar e aprender entre diferentes conteúdos de Matemática

\begin{tabular}{|c|c|c|c|c|c|c|}
\hline \multirow{3}{*}{ CONTEÚDOS DE MATEMÁTICA } & \multicolumn{6}{|c|}{ PROFESSORES (\%) } \\
\hline & \multicolumn{3}{|c|}{$\begin{array}{l}\text { Maior conforto para } \\
\text { ensinar seus alunos }\end{array}$} & \multicolumn{3}{|c|}{$\begin{array}{l}\text { Maior dificuldade } \\
\text { dos alunos }\end{array}$} \\
\hline & 2008 & 2009 & 2010 & 2008 & 2009 & 2010 \\
\hline Equação do 2 Grau & 41,1 & 53,2 & & 5,4 & 7,1 & \\
\hline Função afim & 19,8 & 32,6 & & 7,5 & 9,4 & \\
\hline Frações e números decimais & & 39,4 & & & 32,0 & \\
\hline Geometria & 30,5 & 39,0 & 33,8 & 25,1 & 30,0 & 31,3 \\
\hline Gráficos & & 44,2 & & & 7,2 & \\
\hline $\begin{array}{l}\text { Progressão Geométrica/ } \\
\text { Quadrática }\end{array}$ & 10,6 & 19,2 & & 5,7 & 10,3 & \\
\hline Progressão aritmética & 27,0 & 42,3 & & 4,3 & 3,5 & \\
\hline Trigonometria & 16,5 & 26,0 & 3,1 & 61,9 & 50,2 & 18,0 \\
\hline Equações & & & 29,4 & & & 5,8 \\
\hline Progressões & & & 4,7 & & & 1,1 \\
\hline Função exponencial & & & 1,0 & & & 3,8 \\
\hline Combinatória e probabilidade & & & 4,7 & & & 17,3 \\
\hline $\begin{array}{l}\text { Matrizes e sistemas } \\
\text { de equações }\end{array}$ & & & 3,2 & & & 2,1 \\
\hline Outra & 4,5 & 15,8 & 6,9 & 5,0 & 7,9 & 4,2 \\
\hline Não respondeu & 28,3 & 12,3 & 18,0 & 12,2 & 12,5 & 18,9 \\
\hline
\end{tabular}

Fonte: Avaliação externa do Multicurso Matemática ensino médio ES 2008, 2009, 2010.

Em relação às dificuldades dos alunos, segundo os professores, encontrou-se certa correspondência, ou seja, Trigonometria está, igualmente, entre os conteúdos que o aluno tem mais dificuldade para aprender. Destaca-se, ainda, a Geometria que, segundo um terço dos professores, é um dos conteúdos que traz dificuldades para os alunos.

Foi perguntado aos professores se todos os conteúdos tinham sido trabalhados, e os motivos pelos quais não conseguiram trabalhar toda a matéria prevista. Nos três momentos de avaliação foi pouco expressivo o índice daqueles que conseguiram trabalhar os conteúdos previstos. A impossibilidade de ensinar os conteúdos apresentou razões diversas. Destacou-se, em 2008, 2009 e, com menor ênfase em 2010, a falta de tempo disponível e de conhecimentos anteriores por parte dos alunos. Outro ponto de destaque foi que os professores, de forma geral, não consideraram que a falta de condições de trabalho tenha contribuído significativamente para não conseguirem ensinar todo o conteúdo previsto. 


\subsubsection{PERCEPÇÕES DOS PROFESSORES:}

\section{ASPECTOS CONTEXTUAIS, MOTIVAÇÃO}

\section{E PRÁTICAS PEDAGÓGICAS ADOTADAS}

A pesquisa sobre fatores associados ao aumento do desempenho dos alunos, bem consolidada no cenário internacional e brasileiro (BROOKE; SOARES, 2008), tem enfatizado a relação do resultado educacional com indicadores contextuais e as contribuições expressivas dos diferentes agentes escolares (professores, coordenadores e diretores) na constituição de uma cultura da unidade escolar que impacta na aprendizagem e no bom desempenho dos alunos, configurando o que se convencionou denominar de efeito escola. Por esse motivo, a avaliação do Multicurso Matemática conferiu centralidade à investigação desses aspectos em todas as fases da pesquisa.

Verificou-se que, segundo os professores, ${ }^{2}$ na comparação entre 2008 e 2010, o problema da falta de recursos financeiros se ampliou em cinco SRE: Barra de São Francisco, Cariacica, Nova Venécia, São Mateus e Vila Velha. Para os docentes, esse problema, em 2010, foi menor nas SRE de Afonso Cláudio, Cachoeiro de Itapemirim, Carapina, Colatina, Guaçuí e Linhares.

A falta de pessoal, por sua vez, dimensão que agrega a carência de profissionais administrativos, de apoio e de professores para as disciplinas, está representada no Gráfico 5, em que os valores positivos indicam o problema da insuficiência de recursos humanos nas escolas e os valores negativos indicam a baixa frequência desse problema. Para os professores, a situação em 2010, em comparação com 2008, estava, em níveis diversos, mais favorável em cerca da metade das SRE, sejam elas Afonso Cláudio, Carapina, Cariacica, Colatina, Linhares e Nova Venécia. Pelo contrário, nas SRE de Cachoeiro de Itapemirim, Guaçuí e São Mateus a situação, segundo os professores, teria se agravado. 
GRÁFICO 5 - Falta de pessoal (índice médio padronizado), em 2008 e 2010, por SRE

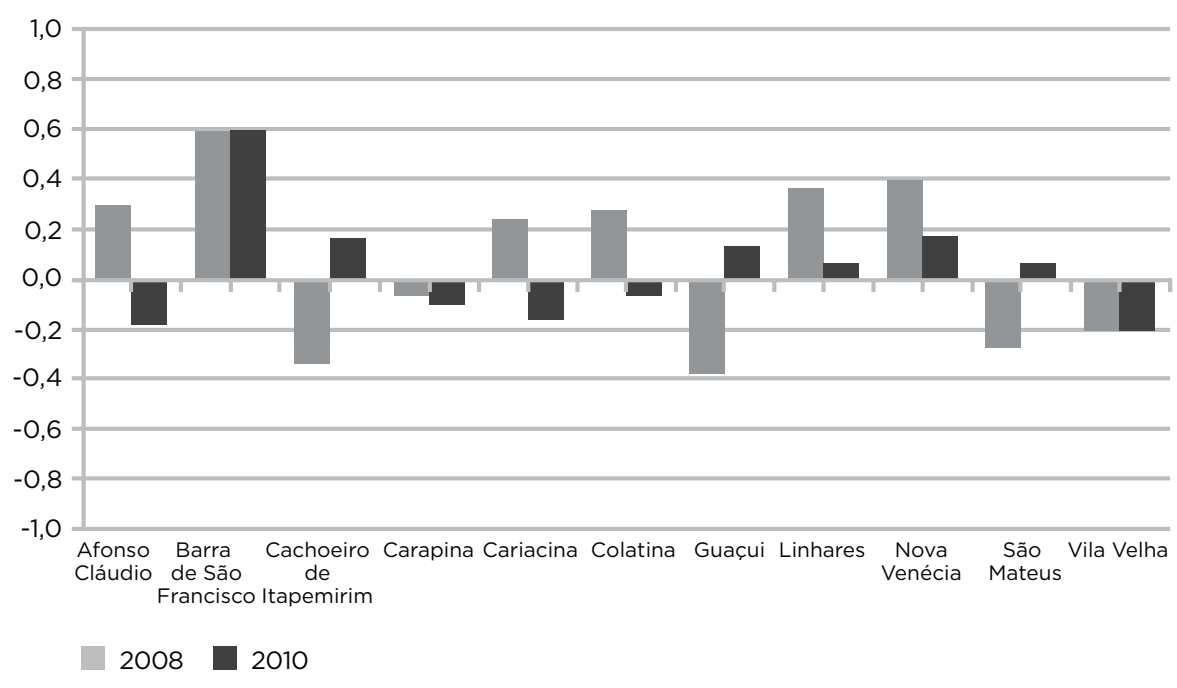

Fonte: Avaliação externa do Multicurso Matemática ensino médio ES 2008 e 2010

\subsubsection{MOTIVAÇÃO E PRÁTICAS PEDAGÓGICAS ADOTADAS} PELO PROFESSOR

O Gráfico 6 mostra os resultados, por SRE, dos níveis de disposição/motivação para o trabalho docente, apresentados pelos professores do Multicurso Matemática. Nesta dimensão são consideradas: a satisfação com o salário, a energia para trabalhar, o grau de estímulo com o trabalho desenvolvido, entre outros aspectos. Destacaram-se os resultados diferenciados positivamente da SRE de Barra de São Francisco. No entanto, de forma geral, houve queda nos níveis de disposição e motivação para o trabalho por parte dos professores da maioria das SRE, quadro compatível com a realidade apresentada pelo professorado da rede pública de outros Estados, analisada em vários estudos da última década (UNESCO, 2003, 2004; OLIVEIRA et al., 2004). 
GRÁFICO 6 - Disposição/Motivação para o trabalho (índice médio padronizado), em 2008 e 2010, por SRE

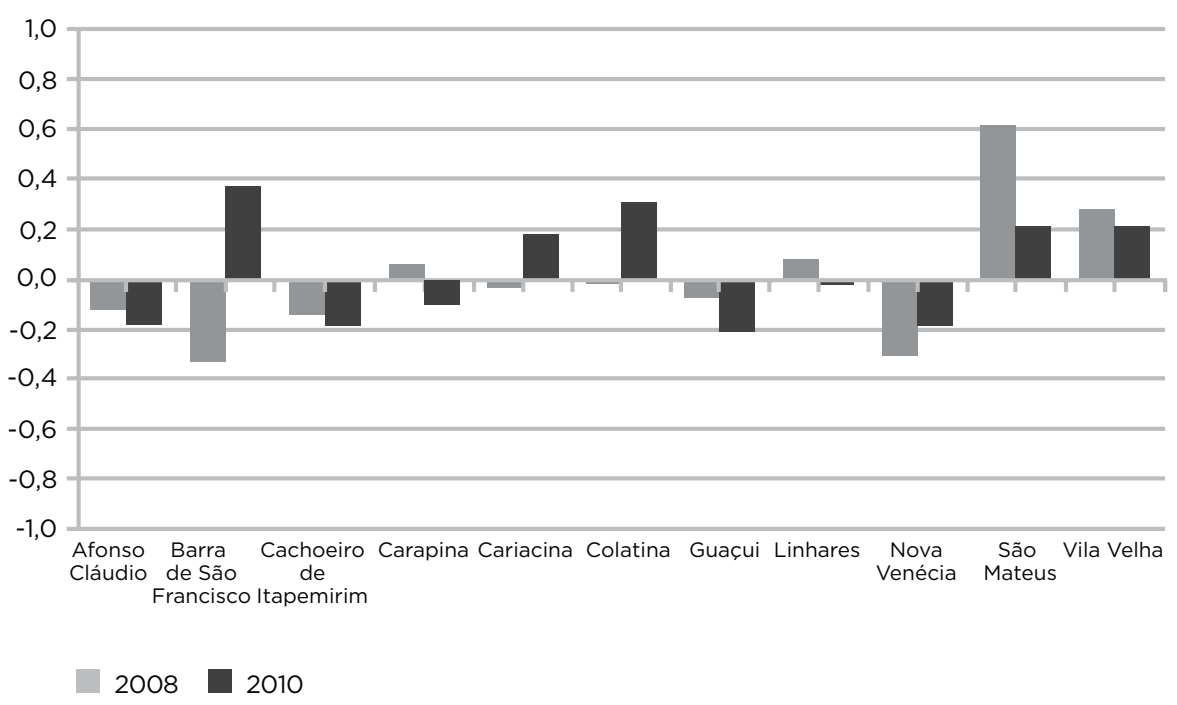

Fonte: Avaliação externa do Multicurso Matemática ensino médio ES 2008 e 2010

Um dos aspectos relevantes do processo de ensino-aprendizagem é a avaliação do aluno. A utilização de diversas formas de avaliação pode oferecer diferentes visões sobre como os alunos estão aprendendo os conteúdos ensinados, favorecendo diagnósticos mais acurados da aprendizagem. Na comparação entre 2010 e 2008, houve maior diversificação nas práticas avaliativas apenas nas SRE de Afonso Cláudio, Carapina, Guaçuí e Nova Venécia. Já nas SRE de Barra de São Francisco, Cachoeiro de Itapemirim, Cariacica, Colatina, Linhares, São Mateus e Vila Velha, os resultados da comparação foram menos favoráveis, apontando piora.

O Gráfico 7 apresenta situações distintas em relação ao uso de recursos pedagógicos pelos professores de Matemática nas SRE, na comparação entre 2008 e 2010. Enquanto cerca da metade das SRE, isto é, Afonso Cláudio, Barra de São Francisco, Cariacica, Colatina e Guaçuí evidenciaram, em 2010, melhores índices do que os encontrados em 2008, as SRE de Cachoeiro de Itapemirim, Carapina, Linhares, Nova Venécia, São Mateus e Vila Velha, no mesmo período, indicaram declínio nos índices de utilização de recursos pedagógicos. Os contrastes negativos mais expressivos foram em São Mateus e Vila Velha. 
GRÁFICO 7 - Frequência de Uso de Recursos Pedagógicos (índice médio padronizado), em 2008 e 2010, por SRE

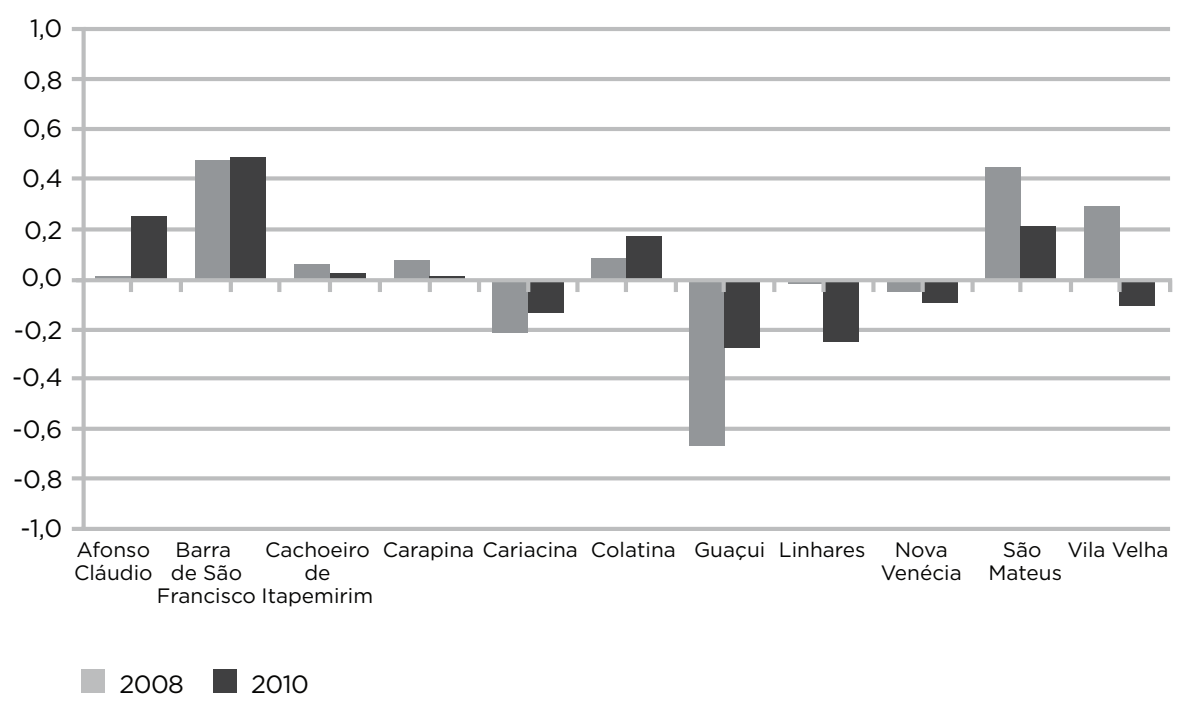

Fonte: Avaliação externa do Multicurso Matemática ensino médio ES 2008 e 2010

\subsubsection{PERCEPCÕ̃ES DOS PROFESSORES:}

O MULTICURSO MATEMÁTICA E SUAS CONTRIBUIÇÕES

Em 2010, a maioria dos professores destacaram, com níveis diversos de concordância, as contribuições que o programa Multicurso propiciou: maior segurança em relação aos conteúdos que ensinavam, uso de materiais pedagógicos mais criativos e melhoria no aprendizado e motivação dos alunos para estudar Matemática.

TABELA 4 - Proporção de professores que atribuíram concordância Total ou Média em diferentes aspectos proporcionados pelo Multicurso - 2010

\begin{tabular}{l|c|c}
\hline & \multicolumn{2}{|c}{ PROFESSORES (\%) } \\
\cline { 2 - 2 } ASPECTOS PROPORCIONADOS & Nível de concordância \\
\hline $\begin{array}{l}\text { Sinto-me mais seguro (a) em relação aos } \\
\text { conteúdos que ensino }\end{array}$ & 49,6 & 34,5 \\
$\begin{array}{l}\text { Percebo que houve melhoria no aprendizado } \\
\text { dos alunos }\end{array}$ & 33,9 & 41,5 \\
$\begin{array}{l}\text { Sinto-me motivado para buscar materiais } \\
\text { pedagógicos mais criativos }\end{array}$ & 52,3 & 36,6 \\
$\begin{array}{l}\text { Percebo que houve melhoria na motivação } \\
\text { dos alunos para estudar matemática }\end{array}$ & 32,7 & 38,3 \\
$\begin{array}{l}\text { Aumentou a chance de compartilhar problemas } \\
\text { e práticas pedagógicas com os colegas }\end{array}$ & 45,4 & 37,2 \\
\hline
\end{tabular}

Fonte: Avaliação externa do Multicurso Matemática ensino médio ES 2010. 
Os professores ressaltaram o trabalho em colaboração com os colegas como decisivo para seu aproveitamento no Multicurso Matemática. Consideraram, ainda, que o programa foi bastante útil para sua prática pedagógica, atendendo às suas expectativas. Em 2010, apenas 16,4\% dos participantes da pesquisa indicaram que o Multicurso não ajudou a melhorar a sua prática como professores. E quase a totalidade dos docentes destacou que procurou participar de todas as atividades do Multicurso.

Considerando todas as SRE, o percentual de professores que, em 2010, disseram pretender continuar utilizando os materiais do Multicurso Matemática foi bastante elevado (cerca de 90\%). A frequência de utilização desses materiais por parte dos professores, entretanto, foi diversa, destacando-se o Livro do professor como o mais utilizado, semanalmente e quinzenalmente. Já as Fichas de Matemática e Cidadania foram os recursos menos utilizados por, aproximadamente, 75\% dos professores pesquisados em 2010.

No que se refere à utilização de Fitas de vídeo e/ou DVD como recurso pedagógico, verificou-se que, em 2010, a maioria dos docentes $(58,4 \%)$ indicou utilizar esses materiais algumas vezes por semana. Ainda que baixo, chamou a atenção o percentual dos docentes que não utilizavam porque a escola não dispunha desses recursos.

\section{CONSIDERAÇÕES FINAIS}

Expostos os principais dados mensurados na avaliação externa do Multicurso Matemática, são apresentadas nesta seção algumas considerações sobre estes resultados, suas relações com os objetivos do programa e suas contribuições para o aperfeiçoamento da qualidade dos processos de ensino-aprendizagem no Brasil.

O Multicurso Matemática configura-se como proposta de intervenção no ensino médio, última etapa da educação básica brasileira, destinada à consolidação e ao aprofundamento dos conhecimentos adquiridos no ensino fundamental, à preparação básica para o trabalho e a cidadania, ao aprimoramento do educando como ser humano e à compreensão dos fundamentos científico-tecnológicos dos processos produtivos. É em relação a essa conjuntura desafiante que as próximas indicações devem ser consideradas. 
No que se refere ao aperfeiçoamento da aprendizagem em Matemática, os resultados mostram que a proficiência dos alunos cresceu de forma discreta, porém progressiva, em todo o período considerado na pesquisa. Portanto, a diferença na comparação do desempenho dos alunos é positiva.

Contudo, se considerados os perfis dos alunos, a evolução da aprendizagem apresenta diferenciais. Neste sentido, dialogam com as pesquisas educacionais sobre este assunto, inclusive no que se refere à equidade de desempenho escolar, por gênero e cor. Na pesquisa apresentada por Soares (2004), por exemplo, no Brasil os alunos que se autodeclaram brancos têm melhor proficiência quando comparados com alunos que se consideram pretos; e em Matemática os meninos têm melhor desempenho que as meninas. Na avaliação do Multicurso Matemática, essas frequências também foram confirmadas. Trata-se, portanto, de um dado importante que reitera a situação de inequidade já observada em outras avaliações, e demanda estudos que proponham políticas públicas e projetos educacionais mais equânimes.

Em consonância com os dados encontrados em pesquisas educacionais no Brasil, mantêm-se como desafios a serem enfrentados pela Sedu-ES:

- os índices dos alunos das classes noturnas, que permanecem com menor desempenho em relação aos demais;

- o crescimento progressivo do número de alunos que estudam e trabalham ao mesmo tempo.

No que concerne à apropriação de princípios e materiais do Multicurso Matemática e aos aspectos relacionados a essa apropriação, ressalta-se, no período analisado, o crescimento das expectativas positivas dos professores em relação aos seus alunos, dos níveis de colaboração docente, e da ênfase conferida às práticas pedagógicas contextualizadas. Além disso, as dificuldades conceituais dos professores foram sendo identificadas e enfrentadas, obtendo-se sucesso, conforme os próprios docentes alegaram.

Considerando a avaliação amplamente positiva do Multicurso Matemática, pelos professores, como programa de formação continuada, é possível sugerir que os resultados do programa, em relação a esses docentes, sejam, neste momento, 
mais visíveis no âmbito das ações do próprio Multicurso, sem que os efeitos tenham se irradiado com a mesma intensidade e qualidade nas escolas, o que pode ser explicado pelo fato de que outros atores envolvidos, tais como gestores escolares, não participaram do mesmo processo.

De toda forma, cabe assinalar uma grande diversidade entre as SRE no que diz respeito à motivação, às práticas e possibilidades dos professores, sugerindo que em outras análises a pesquisa possa inserir estudos contextualizados localmente, a fim de traçar uma evolução precisa dos resultados.

Para tanto, recomenda-se que, em outras análises, seja enfatizada a pesquisa de natureza qualitativa, em todas as fases, para que possa contribuir com a compreensão dos aspectos contextuais que motivem tais diversidades entre as SRE.

Propõe-se, também, em especial, um estudo de caso junto a professores, diretores, coordenadores e alunos da SRE de Afonso Cláudio com o objetivo de identificar quais aspectos contribuíram de forma constante para o desempenho positivo dos alunos.

Finalizando, espera-se que este artigo, com a análise do ciclo 2008-2009-2010 do programa Multicurso Matemática, além das contribuições verificadas no que concerne à melhoria da qualidade dos processos educacionais, forneça subsídios para a tomada de decisões e para o aprimoramento das práticas de ensino-aprendizagem, e que a discussão dos seus resultados inspire os atores envolvidos a buscarem alternativas para a construção de uma educação pública de qualidade para todos, não somente em relação aos conteúdos de Matemática e não apenas no Estado do Espírito Santo, mas em relação às demais disciplinas e em todo o território nacional.

\section{REFERÊNCIAS}

ALBERNAZ, Ângela; FERREIRA, Francisco H. G.; FRANCO, Creso. Qualidade e equidade no ensino fundamental brasileiro. Pesquisa e Planejamento Econômico, Rio de Janeiro, v. 32, n. 3, 2002.

BOAVENTURA, Edvaldo M. Metodologia da Pesquisa. São Paulo: Atlas, 2009.

BROOKE, Nigel; SOARES, José Francisco (Org.). Pesquisa em eficácia escolar: origens e trajetórias. Belo Horizonte: UFMG, 2008. 
COLEMAN, James S. et al. Equality of educational opportunity. Washington, DC: Government Printing Office, 1966.

CUNHA, Luiz Antônio. Educação e desenvolvimento social no Brasil. Rio de Janeiro: Francisco Alves, 1975.

FRANCO, Creso; MANDARINO, Mônica; ORTIGÃO, Maria Isabel. Projeto pedagógico de escola promove eficácia e equidade em educação? Revista Undime, Rio de Janeiro, v. 7, n. 2, p. 30-46, 2001.

GIL, Antonio Carlos. Métodos e técnicas de pesquisa social. 5. ed. São Paulo: Atlas, 1999.

LAREAU, Annette. Social class differences in family-school relationships: the importance of cultural capital. Sociology of Education, v. 60, p. 73-85, Apr. 1987.

MINAYO, Maria Cecilia de S. (Org.). Pesquisa social: teoria, método e criatividade. 22. ed. Petrópolis: Vozes, 2003.

OLIVEIRA, Dalila A. et al. Transformações na organização do processo de trabalho docente e o sofrimento do professor. Revista Mexicana de Investigación Educativa, México, n. 20, v. 9, jan./mar. 2004.

ORGANIZAÇÃO DAS NAÇÕES UNIDAS PARA A EDUCAÇÃO, A CIÊNCIA E A CULTURA. ABRAMOVAY, Miriam et al. (Coord.). o Perfil dos professores brasileiros: o que fazem o que pensam o que almejam. São Paulo: Moderna, 2004.

ORGANIZAÇÃO DAS NAÇÕES UNIDAS PARA A EDUCAÇÃO, A CIÊNCIA E A CULTURA. ABRAMOVAY, Miriam; CASTRO, Mary (Coord.). Ensino médio: múltiplas vozes. Brasília: Unesco, MEC, 2003.

SAMMONS, Pam et al. Key characteristics of effective schools: a review of school effectiveness research. London: Office for Standards in Education, 1995.

SILVA, Nelson do V.; HASENBALG, Carlos. Tendências da desigualdade educacional no Brasil. Dados, Rio de Janeiro, v. 43, n. 3, 2000.

SOARES, José Francisco. Qualidade e equidade na educação básica brasileira: a evidência do Saeb-2001. Archivos Analíticos de Políticas Educativas, v. 12, n. 38, 2004. Disponível em: <http://epaa.asu.edu/epaa/ v12n38>. Acesso em: set. 2011.

WILLMS, Jon Douglas. Proposal for the measurement of socioeconomic status for the focused component of the student questionnaire for the OECD Programme for International Student Assessment. Paper prepared for use by country experts and the Technical Advisory Group of the OECD/Pisa, 1998.

\section{ELIANE BIRMAN}

Consultora educacional

birmaneliane@gmail.com 
ISA CRISTINA DA ROCHA LOPES

Coordenadora de capacitação do Instituto Coca-Cola Brasil

isacristinalopes@gmail.com 